\title{
Introduction
}

\section{Matthias Freise}

\section{PRELIMINARY REMARKS}

$\mathrm{M}$ any scholars around the world are inspired by Mikhail Bakhtin's ideas. For them, his using of the term "dialogue" is one of the key concepts in the humanities. Despite the abundance of interpretations of Bakhtin's teachings, two fundamental questions regarding his "dialogism" still seem to be unanswered: first-do the objects of other humanities have dialogical qualities similar to those literature has; second-how can we define a dialogic method of research in the humanities in general, what would be the specific qualities of such a method? In this volume, seven scholars-from different countries, rooted in different cultures, working in different fields of the humanities - propose answers to the following questions: What in my field of study can be considered a dialogic approach and why is a dialogic approach essential in my field in order to disclose the specific qualities of the material to be analyzed? From these two fundamental questions, the specific questions in the respective fields of study arise: How dialogic is the intercultural encounter in contemporary cinema? What is dialogic design? What are the presuppositions of a successful therapeutic dialogue? On what terms can literary history be called dialogic? How dialogic is postmodern authorship? How dialogic are Plato's philosophical dialogues? What distinguishes a dialogical sociology?

\section{THE HUMANITIES AS A RELATIONAL SCIENCE}

From a disciplinary point of view, the above questions seem to be rather disparate. It is therefore necessary to explain how they are bound together to a common, truly Bakhtinian approach in the humanities. As different as 
the problems are that we encounter in our fields of study, there is one central aspect we all have in mind. Mainstream research and practice in the humanities tend to treat their phenomena as "objects" with "properties." This, we are convinced, is not the proper and necessary approach to what we encounter in our disciplines because what the humanities are mainly and commonly concerned with are phenomena of relationship. Such phenomena require specific_namely, dialogic_-approaches.

All contributions in this volume are inspired by the idea that a dialogic approach in their field is necessary, even inevitable. Therefore, they appeal for substantial change in the methods of their field. They argue that recent methods of research in the humanities are widely unsuitable for the phenomena they examine. How can this be, despite all erudition? Against the background of a highly "speculative" thinking in the humanities up to the nineteenth century, in the twentieth century the humanities very much endeavored to become more "scientific." This was, of course, most respectable, but in consequence has guided research further and further away from what could be called a specifically humanitarian approach, designed for the specific dialogical nature of the phenomena to be examined. The humanities, despite having produced more "exact" results than ever, became more and more unspecific in their fields. We are convinced that the scientification of the humanities at the cost of the specificity of their research may result, paradoxically, in the loss of their scientific basis.

Therefore, a dialogical method in the humanities is not yet an "alternative" approach. It is, rather, a guideline for finding the most appropriate access to what the phenomena of the humanities in fact are: relationships. Sociology should investigate social relationships, not countable mental properties of individuals. Philosophy (again) should investigate the relationship of the human mind with the world, not the properties of language. Literary history should investigate the relationship to the past, and neither what "objectively" happened nor what we construct to be our history. Theory of design should investigate how design is guided by our encounter with the material world and not by the practical function of a tool. Theology should be concerned with our relationship to God, not with rules fixed in a codex. Psychology should not only understand psyche as a living network of relationships, but should also understand the relationship of the therapist to his or her patient as a bi-personal field. Literature, last but not least, consists of relationships that are neither "objective" nor "subjective," but rather establish cultural "neurons" that form not only a cobweb in which we entangle ourselves (Max Weber, Clifford Geertz) but one that opens a wide, even endless semantic space for us to move. This space doesn't bind us, it sets 
viii | Introduction

us free. There are special techniques necessary to move within this field and to sketch the streamlines of it.

It is, however, noteworthy that our attempts to propagate and legitimate dialogic approaches in our fields expose certain significant differences. This can be seen especially in Boháček's philosophical account of Plato's dialogues, and in Kaczmarczyk's using them to expose an existential concept of dialogue. Boháček examines Plato's philosophical dialogues for their inherent dialogic quality, while Kaczmarczyk emphasizes that, in some of them, the existential attitude of the participants is necessary to form a "dialogical" dialogue. These approaches are not just "different," they also expose the two opposite sides of the same problem: for Boháček, the "internal" necessity of the communication to have a dialogic structure, and for Kaczmarczyk, the "external" necessity of the participants to have an existential attitude, which alone opens them to real dialogue. Thus, they are both true, just as both sides of a relationship are equally true. Here, we have a living example of how the dialogue between two disciplines can and should be dialogic.

There is, however, one problem shared by all disciplines in the humanities, in case they, as they ought to, investigate relationships. Relationships, in contrast to objects, are invisible. Rigid scholars conclude that, precisely for this reason, they simply do not exist. There is no such thing as a love relationshipjust hormonal processes in the brain; there is no social relationship-just needs to be satisfied; there is no relationship to the past-only traces and objects left over for examination; there is no relationship within art-just material form and content to take notice of; there is no relationship to the world to be understood by philosophy - only understandings materialized in language; no relationship to the Divine-only religious needs. Of course, we can ignore non-object phenomena, but there is at least one field of relationship that hardly can be ignored, and that is language. Ferdinand de Saussure proved that language consists not of objects but of relationships, which are labelled by the term "sign." "Sign" is the expression of a relationship. Most illustrative here is the case of phonology. Before de Saussure, linguists believed that language consisted of sounds. After de Saussure it became clear that it consists of differences between sounds; that is, it consists of relationships. A phoneme is not an object, but a relationship. You cannot investigate the functioning of language without these differences, which cannot be heard directly but have to be reconstructed by juxtaposition.

The analysis of language as a relationship is called semiotics. It is a long way, however, from semiotics to an understanding of all phenomena of the humanities being dialogic. After the "semiotic turn" in the 1960s and 1970s all fields in 
the humanities were subordinated to language. Everything was language. This is typical with the humanities and their "turns." Given the "relational" character of one humanitarian discipline, scholars conclude that all cognate disciplines are derivations of the one in which this character was encountered. In fact, there is no leading discipline in the humanities. Philosophy is not dialogic "because it consists of language," but it is dialogic in the same regard that language is. It has its own specific dialogic character which has to be explained within philosophy. As a result, we do not harken "back to semiotics." Even scholars within semiotics themselves have not fully understood the relational character of the sign. They never performed the mental leap from description to interpretation, because interpretation seemed arbitrary to them. Here, the hard labor of convincing them is necessary. And this labor can be provided by literary scholarship because literary scholarship successfully developed strategies of plausibility within a field of concurring interpretations. Of course, even philology has recently tended toward "scientification." Digital humanities, cultural transfer research, neuronal reception research, and the revival of the sociology of literature dominate the scene. However, literary analysis has developed the tools to illuminate semantic spaces provided by the "neurons" of literary texts. Therefore, it could serve as a pioneer for an alliance between scholars equally frustrated by mainstream "exact" research in the humanities. It is this mainstream that also tends to repel students at universities. Students expect, for example, genuine philosophical understanding, but teachers convince them that "truth is what is the case." At German universities an average of ninety percent of philosophy students drop out before the bachelor of arts exam. Mainstream philosophers would argue that students expect from philosophy mere "metaphysical speculation" and are not ready to accept that philosophy requires logics, logics, and logics. Relationships, however, are no less logical than objects, but the logics of relation are different from the logics of property.

The primary aim of the contributions in this volume is to restore for the humanities the goal of dialogic understanding, which requires interpretation. All contributors formulate the dialogic character of the phenomena they investigate or of the method they develop. They are convinced that such an approach is able to give a fresh outlook on their field of study. At the same time, by sharing a dialogic method, we get the chance to unite the humanities in a common scientific effort. This provides the humanities with new epistemological power-one that is highly needed, and not only for the humanities as a field of study. The humanities are not, in fact, a luxury with which we indulge 
$\mathbf{x} \mid$ Introduction

ourselves once we have fulfilled our basic needs. The disciplines contributing to this volume-and the humanitarian disciplines not represented here-are able to solve real problems, that is, problems of relationship. Such problems are at least as important as problems we have with objects. And more than a few of the problems we believe to have with objects we might turn out to have with relationships.

In what follows, I will trace earlier efforts to find the uniting principle of the various disciplines within the humanities. Further, I will try to explain what kind of radical switch in our brain is necessary to investigate relationships instead of objects. Again and again we are tempted to go back into the object mode, and then our insight into the phenomena of the humanities is instantly blinded. It is especially hard to adopt the idea that relationships are prior to objects, but some thinkers before us understood this well: above all, Immanuel Kant, the true pioneer of "relational" understanding.

\section{DILTHEY'S SEARCH FOR A COMMON GROUND IN ALL FIELDS IN THE HUMANITIES}

Together with Wilhelm Windelband, Wilhelm Dilthey was the first thinker who made an effort to define the common research principle in the humanities after they had split into a plethora of disciplines. He saw the problem of legitimation which the humanities were facing after the end of idealistic thought. The humanities were accused of having no object, and not undeservedly. For idealistic thought, it had been no problem to reflect on the world without having a real object because this thought was sure to be meta-physic, that is, pre-empiric, investigating processes that were prior to all possible objects. But since then, the winds of science have changed dramatically, and science without an object is no longer taken seriously. "Scientific" science had to have objects. Therefore, the solution Dilthey aimed at was to demonstrate that the humanities also have objects.

But, like many of his contemporary philosophers at the end of the nineteenth century, he was convinced that the key to having an object would be in psychology, since what all fields in the humanities seemed to have in common was a sort of psychological substrate, obviously reliant on acts of thinking. This substrate could be investigated, and there would be the necessary object, and the desired recognition by non-humanitarian sciences. This is why Dilthey gave the 1894 treatise in which he performed his ultimate effort to find the 
common ground for all fields in the humanities the title Ideas On a Describing and Parsing Psychology. ${ }^{1}$

Windelband, in exactly that same year, defined the humanities ${ }^{2}$ as "ideographic," that is, as dealing with concrete single phenomena, while the natural sciences were "nomothetic" as they generate general laws by reductive abstraction. Windelband's prototype for ideographic thought was historiography. Was this already the answer to Dilthey's problem? It was not, because ideography indeed has an object, but all it can do with it is to register it. Like historicism, the mainstream school of historiography at the end of the nineteenth century, it has no tool to interconnect data in order to transform historical knowledge into an understanding that could rival the interconnectedness between natural phenomena reconstructed by natural science. Therefore, for Dilthey historistic historiography could only be a prolegomena to the humanities; it has an approach, but not a method. This is why Dilthey, in addition to Windelband, reached out for psychology.

Dilthey knew it was a difficult task to ground the humanities in psychology without losing their specific strengths, which are logics and rationality. This is why he begins his argument, surprisingly, with the obviously outdated "rational psychology," developed 200 years earlier by Christian Wolff. Hastily, he adds "well, Kant has proved its impossibility," but then why mention it right in the beginning? Because what Dilthey needs is a combination of Wolff's strict rationality and the post-idealistic "real" substrate to be analyzed. This is obviously forcing square pegs into round holes. But Dilthey was persistent. He writes that, at least after Kant, it was still possible to derive general laws. And according to Kant, besides outer experiences, we have also "inner experiences." Aren't these experiences psychic after all? Shouldn't we be able to parse them? And arrive through them at the structural interrelation between all fields in the humanities? But these rhetorical questions are, unfortunately, mere declarations of intent with no indication on how this should be done in a scientific practice. And this is not by chance. Psychology cannot be, as Edmund Husserl argued, the basis of the humanities. In his Logical Investigations (1900) Husserl demonstrates that if mathematical numbers were based on the mental praxis of

1 Wilhelm Dilthey, „Ideen über eine beschreibende und zergliedernde Psychologie“ [Ideas On a Describing and Parsing Psychology], in Gesammelte Schriften, vol. 5 (Berlin: Teubner 1924), 193.

2 In a speech delivered in 1894 in Strassburg and published in that sameyear (Wilhelm Windelband, Geschichte und Naturwissenschaft [History and science] [Straßburg: Heitz, 1894]). 
counting, that is, on psychology, mathematics as a whole would be ridiculously dependent on states of mind, on feelings and likes. It would become "impure" and would cease to be mathematics at all. It must have been God who created at least the integers. ${ }^{3}$ But in a way Husserl was an unfortunate seeker like Dilthey. Leszek Kolakowski in his book Husserl and the Search for Certitude 4 portrays Husserl's desperate attempts to overcome the "crisis of European thought" (this being the title of Husserl's last monograph) by giving knowledge a new solid ground to stand on. With his "stern science," he would not fall into the trap of psychology like Dilthey. Phenomenology at its best has been giving descriptions of what is going on in relationships. ${ }^{5}$ But the reason why Kolakowski states Husserl's attempt was a failure is that it remains unclear on what epistemological grounds phenomenological argument would be based on. Husserl himself would have argued that phenomenology is only a method, not a theory, and therefore carries its epistemological grounds within itself. But nevertheless, a theory is needed, because the humanities, like the natural sciences, have to answer the question of what kind of general "properties" qualify a phenomenon to be a subject to their method. ${ }^{6}$

Another trap - that only at first glance is more convincing than grounding everything in psychology — is grounding everything in language. The argument here is similar. Because all knowledge in the humanities is formulated in language, just examine the language and you gain the common ground of all humanitarian argument. But language is, like the psyche, impure, bearing the traits of all our prejudices and opinions. And this impurity cannot be distilled out of it, not even by inventing a "concept language" (Frege). In philosophy of language, there can be noticed a strategy similar to Dilthey's psychologism (not as obvious, however, but still): the attempt to have some "empirical" material-words, in this case-that would allow us to "observe" instead of merely imagining or implying "principles" that we never can prove, while still "rescuing,"

3 Attributed to the mathematician Leopold Kronecker, comp. Yvon Gauthier, Internal Logic. Foundations of Mathematics from Kronecker to Hilbert (London: Springer, 2002), 122.

4 Leszek Kołakowski, Husserl and the Search for Certitude (New Haven: Yale University Press, 1975).

5 Cf. Maurice Merleau-Ponty's avant-propos “Qu’est-que la phénoménologie?” in his monograph Phénoménologie de la perception [Phenomenolgy of perception] (Paris: Gallimard, 1945).

6 We have to mention here that psychology as Dilthey understood it aimed to be an empirical discipline. Only by "describing" and "parsing" psychic phenomena, the humanities seemed to gain its dignity. What Dilthey could not have in mind was psychoanalysis, as this young discipline seemed to be as speculative as the most esoteric of the humanities. 
at the same time, all the purity and objectivity of Christian Wolff's rationalism. No matter how successful it was, the philosophy of language as founded by Gottlob Frege could not be and did not become the common solid ground of the humanities. But of course language - to be precise, the sign in Saussurean understanding - is a phenomenon of relationship; in other words, it is a dialogic phenomenon. Language, like the psyche, is not the material ground and empirical basis for the humanities. They are both, rather, part of the problem: how can I properly understand psyche and language? By which specific and yet universal properties are psychology and linguistics part of the humanities?

As it should now be clear, it is a seductive shortcut to declare one group of phenomena in the humanities to be the basis for the rest of them. Therefore, the common basis of the humanities can neither be psychology, nor logics, nor even mathematics. ${ }^{7}$ These phenomena are not above the rest of science; they would not solve the problem, because they are part of it. They are part of the problem, because they themselves are relationships. It is impossible to explain one relationship with the example of another one, because the problem would just shift to the next discipline, remaining the same unanswered question. The humanities are full of those shifts, such as "the psyche is social," "cognition is language," or even "literature is what readers make of it," "history is what historians make of it." If you want to investigate the psyche, history, cognition, literature proper, you have to deal with the relationship every of them entails. And if you deal with the material substrate of a humanitarian discipline, like measuring readers' brain zone activities, you gain exact but trivial and unspecific knowledge such as "pornography stimulates sexual brain zones."

But let's return now to Dilthey. Again and again he produced statements such as "the goal of the study of psychological phenomena is their interrelation" ${ }^{8}$ or "inner life is unity." However, he did not reach out farther than stating that "connection is primarily given" 10 and "structural connection is experienced." 11 It is frustrating to read this-you want to shake him, asking: yes, of course, you're right, but please explain how it is experienced and what

7 See Derrida on Husserl's "Philosophie der Arithmetik": Jacques Derrida, La voix et la phénoméne. Introduction au problème du signe dans la phénoménologie de Husserl [Speech and Phenomena: And Other Essays on Husserl's Theory of Signs] (Paris: Presses universitaires de France, 1967).

8 Dilthey, "Ideen über eine beschreibende und zergliedernde Psychologie," 193.

9 Ibid.

10 Ibid, 237.

11 Ibid. 
xiv | Introduction

methodology is used to study it? But Dilthey at least saw the problem and made a real effort not only to formulate it but also to solve it. In his numerous unfinished manuscripts he went on fighting for a solution till his death-in vain. So he left this duty to posterity - either give to the humanities a solid ground of knowledge equal to the knowledge gained by the natural sciences, or to shut down the whole business. His last word in this case was that the natural sciences "explain" while the humanities "understand." However nebulous this may be, it paved the way for a method of understanding that had been previously applied to the study of the Holy Bible by Schleiermacher. This method is called hermeneutics. Is hermeneutics, then, an answer to Dilthey's question? We will see.

\section{HERMENEUTICS}

In one respect hermeneutics is the answer, as it indeed has an object. One could even say that it has the object, that is to say, that it gets ever closer to the one and only object it is heading for. The classical hermeneutic circle is not, of course, a perfect circle but a tool of approximation. And not by chance the theologian Schleiermacher, who invented hermeneutics, had only one objectfor the investigation of the Bible there was by definition only one object, and that was God. But is God really an object for the interpreter of the Bible? For Schleiermacher and his protestant theologian colleagues, God was the absolute truth and the Holy Bible was the exclusive access to this truth. But if someone else whom I encounter or try to encounter is the absolute truth, then in fact not He is my object, but rather I am His object. An object is an object, because I assign my truth to it, and not the other way round. This is the definition of an object. Natural science has objects, because natural science is orientated towards assigning truth to phenomena. ${ }^{12}$ We will come back to this when we address the question of what constitutes a relationship as compared to an object, and what kind of relationship natural science entails. So far we can only ask if hermeneutics could be the one common method of all fields in the humanities.

It cannot be it for several reasons. First of all, Dilthey's problem was to demonstrate the interrelation or the common ground of humanities of various

12 Compare Martin Heidegger's interpretation of Kant's Critique of Pure Reason in Die Frage nach dem Ding [The question concerning the thing] (Tübingen: Niemeyer, 1962). Heidegger's statement in this book, that Kant constitutes "the thingness of the thing" and, through this, objects, is, however, one-sided. Kant with his book may have intended to found the scientific cognition of "objects," but his "Copernican revolution" was, in fact, that he turned away from "objects," beginning to investigate relationships. 
fields. Hermeneutics, as a method, does not connect different humanities. Of course, hermeneutics has been developed not only in theology, but in literary scholarship, in philosophy, and even in history. But it does not create any connection between these fields, because the method does not imply any analogy between what is reachable by the method. Literature is neither comparable to God nor to the historic event. They are completely different types of subjects. But, nevertheless, all kinds of hermeneutics in fact have something very specific in common, but not being "the" method of all fields in the humanities. Rather, they form one specific type within the typology of scientific methods within the humanities.

What all hermeneutics has in common has been formulated in the most extensive description and justification of hermeneutics, ventured by HansGeorg Gadamer. Gadamer's hermeneutics is indebted to the classical understanding of a text as an aspiring ideal (model). A "truth" is concealed in the text that has to be achieved. According to Truth and Method, interpreting a philosophical or literary text, the reader has no freedom whatsoever to stand in a historical distance to it. ${ }^{13}$ The "sense" of the text comes to its "perfection" only through the "application," which for Gadamer means that the reader annihilates all distance to the text and places him- or herself at the position of its addressee. However, a historical research, as Gadamer himself concedes, would never agree with such a method, because for history the "critical distance" to the researched object is constitutive. Therefore, for Gadamer, an understanding or agreement between hermeneuticians and historians is impossible. This is why Jean Grondin, in his highly sympathetic "Einführung in die philosophische Hermeneutik" (1991), ${ }^{14}$ frankly acknowledges that Gadamer never answered the question as to what role historical critique plays within the framework of hermeneutics. In consequence, if hermeneutics is irreconcilable with historical research, it cannot be the universal method of the humanities we are searching for. But again, as hermeneutics is, of course, a form of relationship, it will find its place within the variety of research attitudes in the humanities. It will turn out that hermeneutics is a mode of understanding, which is particularly different from (historical) criticism. Criticism is another "type" of research stance within

13 Hans-Georg Gadamer, Wahrheit und Methode (Tübingen: Mohr, 1965). Translated by Joel Weinsheimer and Donald G. Marshall as Truth and Method (London: Sheed and Ward, 1989), 338.

14 Jean Grondin, Einführung in die philosophische Hermeneutik (Darmstadt: Wissenschaftliche Buchgesellschaft, 1991). Translated by Joel Weinsheimer as Introduction to Philosophical Hermeneutics (New Haven: Yale University Press, 1994). 
xvi $\mid$ Introduction

the humanities, rather than hermeneutics, and only within the framework of a principle that includes both of them will the reason for their respective incompatibility become comprehensible.

Therefore, hermeneutics is not sufficiently universal to be the common method of all fields in the humanities. Moreover, it doesn't give us any clues regarding the connectedness between all possible objects of the method, as it is just a style of proceeding in the effort to understand one object and not a theory. Again we arrive at the point of asking why, after all, we need theory in the humanities. The question is the same one that could be to Husserl, since hermeneutics also has to answer the question: what kind of general "properties" qualify a phenomenon to be a subject of its method?

\section{ERNST CASSIRER}

Although he saw the necessity of a new foundation for the humanities after the fall of idealism, the German philosopher Ernst Cassirer rejected Dilthey's juxtaposition of explaining and understanding sciences. He rejected his psychologism as well. For Cassirer, the common ground for all fields in the humanities, and even not only for the humanities, but for all science, is not psychology but mathematics. He understands mathematics as the science of pure relation, which abstracts from all properties of substances. So what science does is not investigating substances, but relations, which universally can be expressed by the formula $y=f(x)$. From this point of view, in his book Substance and Function, and Einstein's Theory of Relativity, ${ }^{15}$ he criticizes Aristotle for grounding his system of categories on substances with their properties. Although in Aristotle's table of categories the category "relation" does appear, Cassirer states that it does not play any constructive role in his philosophy. Therefore, he calls Aristotle a "substantialist." According to Cassirer, with modernity, the natural sciences freed themselves from Aristotle's substantialism and were mathematized, while within the humanities no one noticed that they were still in the "substantialist" mode.

What Cassirer mentions here is important for my argument, since I stated that the humanities should be the dialogic study of relationships, while the natural sciences rather deal with objects. Is this proposition obsolete with Cassirer's statement? What kind of use does Cassirer make of the concept

15 Ernst Cassirer, Substance and Function and Einstein's Theory of Relativity (London: The Open Court Publishing Company, 1923). 
of "relation" both within and outside of the humanities? Is "relationship" the same in the natural sciences and in the humanities? Are we in the paradoxical situation that those who deal with objects (in natural science) switched to the relational understanding of the world, while those who should deal with relationships (the humanities) are still obliged to objects? First of all, I, of course, agree with Cassirer that a mathematical function is the expression of a relationship. But is it as universal as Cassirer states? Maybe it is not the only one, not even in mathematics. I am not a mathematician, but what I can say is that a function is a specific relation; that is, not all relations are functions. Set theory, for example, goes on well without any notion of function, but it nevertheless comprises a specific form of relationship. Therefore, I would not rule out the possibility that in mathematics it should be possible to discern different forms of relation. But this will be a task for mathematicians, not for me.

Nevertheless, a function is a relation, and as such for our purposes Cassirer is an ally. The thingness of things for him is not a "given," but some kind of crossing in the network of relations. Science analyzes or synthesizes the general rules of connection within this network. But the result of our binding loose ends is nevertheless an object, or, with other words, the thingness of a thing. If we confront this result with Heidegger's interpretation of Kant's Critique of Pure Reason, Cassirer seems to continue not Aristotle's substantialism, perhaps, but the object-orientation of classical metaphysics that was inaugurated by Aristotle. This is exactly what Heidegger criticizes in Being and Time. So, Cassirer and Heidegger might have had a lot more to quarrel about than just freedom, which was the topic of their famous 1929 dispute in Davos. Cassirer is a classical representative of a philosophy of (natural) science. In this respect he is truly an orthodox Neo-Kantian. And, therefore, his understanding of relationship is limited. His catalogue of forms of access to the world-myth, religion, science, language - is connected by the idea that all these accesses are "symbolic forms." What does this mean? According to Cassirer, we "arrange" our sensual data to make them concise, but we have to "stabilize" them through representation.

Representation is what creates "symbolic forms" like myth or language. Therefore, language or myths are "expressions" of relationships. So far so good. But precisely this description of how we establish relationships with the world makes obvious that Cassirer is still in the mode of objects and not in the dialogic mode of relationships. In fact, the "arrangement" of sensual data as well as the stabilization of this arrangement is an example par excellence for establishing an object, not a relationship. The object is "represented" in the symbolic form. 
Our mind uses this "trick" to let certain sensual data stand out from a "context." The result is an object. This is, of course, a departure from substantialism, but it is the "nominalist" departure which suppresses the thing in itself, that is, the partner out there of the dialogue between, for example, man and nature.

Furthermore, Cassirer's symbolic forms are not interrelated. Every category exists independently, which gives no way to a division which constitutes principal variants of relationship, like function, identity, and membership in a set in mathematics. Even if we concede that myth is not a set of stories but a structure, it would be still impossible to understand the relationship between different symbolic forms. According to Cassirer you can say "myth is a language," because both are symbolic forms. But why then discern them? What is specifically different in myth from what is in language? Why do we have myth when we already have language? What in our sensual data determines us to express them as language or to express them as myth? Another example: what is the dividing line between religion and myth? Which logical operation transforms myth into language, or religion into science? All this is simply impossible. And for a set of dialogic relationships, it should be possible.

What really links together all fields in the humanities is that they all examine phenomena of relationship. Phenomena of relationship are subject to different questions and analytical methods than objects. In order to examine relationships, we have to switch into a different mode of cognition. Relationships are not empirically given but rely on our readiness to relate. The acknowledgement of relationship is impossible without interpretation. Interpretation is the readiness to relate. If I abstain from interpretation, I refuse relationship. The approach to relationships can be labelled by different terms. Bakhtin calls it dialogic, but this term is rather emphatic than analytic. To call it the specifically aesthetic approach to reality is correct insofar as art in fact is a phenomenon of relationship. However, this attribute will be widely misunderstood as disinterested pleasure, coined by Kant's aesthetics. Husserl's terms "phenomenological reduction" or "epoché" are based on the most adequate description of what really happens in mind when you switch to the "relationship" or "semantic" mode, but the terms are limited to the sphere of epistemology and will be understood only by specialists. The term "metaattitude" or "meta-approach" is popular among Bakhtinists, ${ }^{16}$ but it suggests that the relationship view stands above the object view. In practice, however, both views are on equal rights. Every relationship can be reframed as an object

16 See also Gary Saul Morson, “The Heresiarch of META,” PTL III (1978), 379-385. 
and vice versa. With such a reframing, we change into an alternative paradigm. The paradigm for objects is the struggle for survival of the human species, the paradigm of environment control and the life and death struggle described by Darwin. With Darwin, what is not object for me makes me its object. Creating objects is our tool to survive by control and therefore there is no reason to discredit it. Man, however, is also able to adopt an alternative attitude, and this attitude is no less essential for us. This attitude, which Bakhtin calls "dialogic," makes it possible to understand ourselves as an integrative part of our surrounding. The relationship aspect of our attitude toward the world is particularly necessary for our mental health. Most of our mental reality consists of relationships.

A science of relationships deals with phenomena which are subject to principles fundamentally different from the principles which guide objects. Therefore, it also requires different methods. ${ }^{17}$ Psychology, for example, should be a classical science of relationship dealing with the relationships between human beings. But even psychology is practiced in two variants. Experimental psychology is an object orientated science that cannot and will not talk about relationships because relationships cannot be verified according to the plausibility criteria accepted by object sciences. On the other hand, psychoanalysis is psychology

17 A shift to relationships might be identified with Rorty's turn from analytical philosophy to pragmatism. There is, however, a fundamental difference. It is absolutely reasonable to discharge, like Rorty, mind and language as solid bases for truth. Rorty's alternative, however, leaves no room for truth at all. His truth can be reduced to the broadest possible circle of people committed to an opinion (see also Richard Rorty, Philosophy and the Mirror of Nature [Princeton: Princeton University Press, 1979], 176). The truth we propose in this volume is not social in Rorty's pragmatic understanding but takes relation as the primary, irreducible source of truth. Relation is not social, it creates the social. Therefore empiric social reality, primary to Rorty, is secondary to us. Another coincidence with our shift from objects to relationships could be seen in Habermas' theory of communicative action (Jürgen Habermas, Theorie des kommunikativen Handelns [Frankfurt: Suhrkamp, 1981]. Translated by Thomas McCarthy as Theory of Communicative Action [Boston: Beacon Press, 1984-1987]). In contrast to the "in-between" designed by Habermas, our "relationship" is not a pragmatic, but a semantic parameter. It is not communication, but pure relation. You can watch people communicating, but you will not see the relation between them. The advantage of our over Habermas' point of view is in the impossibility of what Habermas fears most: pretense, feint, utilizing. The relationship itself cannot be but true, despite all pragmatic art of disguise. On the other hand, it requires interpretation. This does not make void its truth because truth, being a relational phenomenon, can only be achieved by interpretation. "Having" rational truth is a misinterpretation of the access to this kind of truth. For Habermas, truth is a result not of interpretation, but of negotiation. That is the difference between his and our attempt to overcome the absolutism of truth. 
$\mathbf{x x} \mid$ Introduction

in the mode of relationship. Therefore, its plausibility criteria are substantially different from those used by experimental psychology (and therefore are disputed by the latter). I would like to generalize this situation: the humanities exist in two variants - as object-related and as relationship-orientated scholarship. Not in every discipline, however, has scientific practice formed such a clear-cut alternative as in psychology. Psychology, therefore, can be called a model case of double vision within the humanities.

In the dialogic mode, the humanities are the sciences that deal with relationships. Relationships are, as I have stated above, invisible. Therefore, dialogic humanities need interpretation. But before we learn about how different disciplines in the humanities make use of this tool, we must admit that relationships need a specific access to be realized at all. If you do not use this access, you will inevitably end up with objects. This is the main problem if you want to convince someone about the existence of a relationship. He or she could answer: "all I see are objects. And anything besides objects is just a figment." However, we can turn this argument upside down. So, with the same right we can argue that the only thing which really exists are relationships, and objects are mere figments put up by stubborn substantialists. But this will not help us to convince our interlocutors. Perhaps a striking example will help. Everyone knows what a marriage is. A marriage is a relationship by definition. So how can you understand a marriage in a marital conflict, for example? For instance, let's imagine that I visit my sister and she has a marital conflict with her husband. I feel obliged to help because she is my sister. She then tells me what the whole conflict is about, and that her husband is a villain, and that she feels so demeaned by him. What she tells me is convincing, and furthermore she is my sister. Therefore I go to my brother-in-law and tell him that he should stop demeaning my sister and start to behave like a loving husband. He might then tell me, "man to man," what the whole conflict is about, that his wife-that is, my sister-is behaving completely irrationally, and he has been stringing together arguments in an attempt to reason with her but she does not even want to hear them. By the way of presenting his arguments to me, he convinces me that he is right, and then asks me to go to my sister and tell her his truth about the conflict. But if I did, the whole game would start again from square one.

What I received from each of them in this little scene were their respective truths about the relationship, but certainly not the truth of the relationship proper. Through his truth and through hers, there is apparently no access to the truth of the relationship. I will have to free myself from both 
truths, from both positions, in order to get a chance to get hold of the truth of the relationship. This is a well-known procedure in psychology and sociology. In psychology and sociology, to get hold of the truth of the relationship is known as reaching the meta-position, or the position of the supervisor. Supervision is a regular procedure where relationships are the essence of the business - as in schools, kindergartens, or think tanks. But there is one big theoretical problem with the position of the supervisor or the meta-position. To get there, you have to be out of the situation, you must not be part of the situation you supervise. Otherwise you would lack objectivity, and you would not gain the truth of the relationship. This third position, position $\mathrm{C}$, would be the "neutral" position, established by some logicians in addition to the classical logical positions of "true" and "false." But in the second half of the twentieth century, philosophy and cultural theory have demonstrated that such a position is impossible. All we have are positions and viewpoints, and you cannot escape from them. This is what contemporary theory seems to have learned from Heidegger's criticism of Husserl's attempts to find the zero-starting point of sincerity. According to Heidegger, we are always and unescapable already in, that is, in the world. For modern theory this means, that no "objective" criticism is possible and every criticism is "engaged." For example, there is no meta-position in gender questions, because everyone who wants to understand the relationship between men and women is either a man or a woman. Therefore he or she will not be able to argue from a "neutral" position. He is a part of the male discourse and she is a part of the female discourse. All they can do is advocate for their rights. This is why contemporary feminist gender discourse is, must be, and wants to be biased. Another example is the post-colonial discourse. You are either a colonialist or you are a colonized. And whatever you say about the relationships between formerly colonizing and formerly colonized cultures, you are a party in the relationship. There is no way to escape the situation, because right from your birth you belong to one side or the other. Try to venture innocently that you endeavor is "objective" because you are, for example, a professor of cultural studies, and you will do so in vain. You are a European professor of cultural studies or you are an Asian or African one. The furthest contemporary theory can go in the direction of a meta-position is to engage in an infinite process of escape, known by Derrida as "differance" and by Camus as "The Myth of Sisyphus."

However, if we look at Heidegger's argument in a "relational" mode, the lesson he gives us is a bit different. Sure, "being already in" is irreducible. But being already in for us clearly means that relationships are prior to any attempt to get hold of them. You cannot construct, as Descartes and Husserl attempted, 
xxii | Introduction

a "worldless" subject that begins to establish a relationship to the world, since it is the relationship that makes the subject as well as the world. The priority of relationship is the simple truth of being already in-and this is the gist of Heidegger's objection to Husserl.

In psychology, it is similar. If you go to a psychoanalyst seeking help for problems you have in relationship to your social surrounding, as soon as you start your conversation with him or her, naturally you establish a relationship with him or her as well. The analyst becomes part of your social surrounding. And with this he or she is in the situation from which you want to find a way out. Psychoanalysis, however, has developed a method to escape the trap of patients' transference on their analysts. What the analyst is supposed to do is to analyze his or her own countertransference, that is, his or her own projection onto the patient. The prerequisite to make an analysis of countertransference is that the analyst himself in anticipation went through psychoanalysis. This does not make you judge objectively in the strict sense. But, with the help of going through psychoanalysis yourself, you learn about your own insights and blindness, your own truths and untruths. You become ambivalent, and this is natural. Everyone has blindness and sight, everybody's position is true and untrue. And because I recognize my own ambivalence, I am able to acknowledge the ambivalence of others, too. As you see, we don't deal anymore with the position $\mathrm{A}$, the wife, the position $B$, the husband, and above them the position $C$, the supervisor. Now, we have not three, but four "positions" - the truth and the untruth of A, and the truth and the untruth of B. You are part of the relationship, inevitably, but, nevertheless, you are able to "understand" it once you have access to all four positions.

This basic structure of developing a meta within and not above a dialogue resembles Lacan's quadrilateral psychological structure mentioned in the chapter "Voices in Image." Not by chance Xiaojing Wang uses Lacan exactly for the same purpose. She demonstrates the possibility of understanding within a so-called "Oriental" dialogue and not above it, of an understanding which avoids the impossible effort to escape the basic colonial relation. Lacan's quadrilateral structure consists of the big Other, which generates the subject, which generates the little other, which generates the ideal image of the ego. The truth of the other can be called the big Other, it is the primary source of imagining and the ultimate goal of analysis. It generates the truth of the I, which is the secondary source of imagining and the secondary goal of analysis. The little other marks the untruth of the other being the specular image of the subject, while the ego marks the untruth of the I because it comes out of the little other. 
Psychoanalysts need a trick to reach this quadrilateral level of ambivalence, because it is very hard to get rid of your own truth and the other's untruth. The trick is to concentrate on the form of the patient's pronouncements and not on the content. Freud describes this trick in Ratschläge für die psychotherapeutische Behandlung. ${ }^{18}$ The attention to form instead of to content is well known also in literary analysis. The goal is the same - to get rid of the object level in order to reach the relationship level, which in literature means to get rid of the pragmatic level of a text in order to reach the semantic level of it. On the pragmatic level you deal with objects, on the semantic level you deal with relationships, because the semantic level provides you with ambivalences.

In a way, the chapter of this book titled "Attachment Patterns in the Bi-personal Field" can be considered as a supplement to Freud's "advice for therapeutic treatment." Reinhold Plassmann extends the analysis of countertransference, which lays the ground to the double truth and untruth square, with the description of the proper process of interaction in the therapeutic dialogue. In other words, Freud sets the individual presuppositions on both sides for a successful therapeutic dialogue, while Plassmann concentrates on the qualities of the process itself which unfolds between the patient and the therapist under these prerequisites. This is why the efforts collected in this volume cannot be called Freudian: Freud still aims at the individual with its mental disorder, while we consequently start from the relation.

Since chapter 7, which deals with psychoanalytic therapy, explicitly refers to Bakhtin, we should briefly comment on Valentin Voloshinov's book Frejdizm, ${ }^{19}$ which allegedly has been written by Bakhtin and contains some harsh criticism of the psychoanalytic method. Concerning the authorship, there can be observed a throughout fundamental difference of point of view between Bakhtin and Voloshinov. ${ }^{20}$ Even if Bakhtin wrote the Voloshinov books, he provided them with a completely different epistemological position. Bakhtin's own argument is consistently phenomenological, while Voloshinov's argument is based on sociology. Voloshinov argues against "idealism," while

18 Sigmund Freud, "Advice to Doctors on Psychoanalytic Treatment," in Wild Analysis, trans. Alan Bance (London: Penguin, 2002), 31-42.

19 Valentin Voloshinov, Freidizm (New York: Chalidze, 1983).

20 This and the following arguments are based on my book Michail Bachtins philosophische Ästhetik der Literatur [Mikhail Bakhtin's philosophical aesthetics of literature] (New York: Peter Lang, 1993). 
Bakhtin's analytical point of view with good reason can be called idealistic. ${ }^{21}$ Concerning Voloshinov's criticism itself, firstly, we observe the long-outdated argument that Freud subdues man's mental identity to physical drive. Secondly, Voloshinov argues that the unconscious is empirically inaccessible. His alternative is to investigate social reality.

This argument, however age-old it may be, gives us the opportunity to once more underscore the specifics of our approach in this volume. For us, neither psyche nor social "reality" is real. What is real is the encounter, the dialogue, the conflict. This is what first of all produces psyche and the social world. In order to understand a relationship, you should get rid of the positions which form the relationship. In most cases, these positions are called the subject and the object. Therefore, whoever in relation to relationships would use the word "subject" or "object" or "subjective" or "objective," is already out of the game. From these notions, there is no way towards the relational truth of a relationship, regardless of whether you are in philosophy, sociology, history or any other field in the humanities. In my literature classes, these words are strictly forbidden. This "relational" understanding is precisely how we think Freud should be understood: psyche is the product of conflictual relations. This makes Voloshinov's criticism of Freud obsolete.

Of course, it is hard to relinquish attempting to understand a relationship from its participants. It is also hard to imagine, as illustrated by a quote from John Stuart Mill. In his “Examination of Sir William Hamilton's Philosophy," he states: "Can a relation be thought without thinking the related objects between which it exists? Assuredly, no: [. . . when we think a relation, we must think it as existing between some particular objects which we think along with it." ${ }^{22}$ Maybe it is worth having a deeper look into Sir William's writings. However, his adherence to a "relational" understanding cannot be by chance, for he was the most prominent popularizer of Kant's philosophy in Britain, and Kant was the most eager advocate of a "relational" view of reality in the history of philosophy. So, Sir William Hamilton must have understood something very fundamental in Kant's work, but John Stuart Mill apparently could not appreciate this.

21 The whole Bakhtin-Voloshinov identification is based on one article by Vjacheslav Ivanov published in 1973 (in English: Vjacheslav Ivanov, "The Significance of M. M. Bakhtin's Ideas on Sign, Utterance, and Dialogue for Modern Semiotics," Soviet Studies in Literature 11, issue 2-3 (1975): 186-243), when early key texts written by Bakhtin were not yet published. Moreover, Ivanov's argument that Bakhtin wrote the Voloshinov books consists of mere assertions.

22 John Stuart Mill, Examination of Sir William Hamilton's Philosophy, vol. 9 of Collected Works, ed. John M. Robson (Toronto: University of Toronto Press, 1979), 308. 
We should not criticize him for that, for within the framework of thinking there is room either for objects, or for relationships. Mill opted for objects.

A similar case is Ludwig Wittgenstein's early treatise Tractatus LogicoPhilosophicus (1921). According to Wittgenstein, an atomic fact (Sachverhalt) is a combination of objects. ${ }^{23}$ Here, as in Mill's philosophy, objects are prior to relations, which, in Wittgenstein's terminology, are called atomic facts. Not by chance, however, in the following paragraphs of his book Wittgenstein has nothing to tell about objects, he exclusively talks about atomic facts. Wittgenstein does not venture to put relations prior to objects, but implicitly he can be understood in this way. All we have are combinations, expressed as atomic facts. An object is the sum of combinations in which it exists.

In order to understand relationships, you have to adjust yourself to the point of view that a relationship is prior to its participants. To be exact, a relationship, which can also be called a "situation," produces its participants. For example, a murder produces two participants: an offender and a victim. Before the crime, they did not exist. The "offender" was not yet an offender, the "victim" was no victim. Both were installed only by the situation of the murder. This is how you should try to understand how logics could start up from a situation and not from its participants. Mother and child are produced by the situation (relationship) of motherhood. This is shown by a deep examination of the semantics of words. Sigmund Freud through his psychoanalysis gave an important impulse to the change of angle from objects to relationships. This is why he also saw the development of language from a new point of view. In his essay "The Thread Spool Game," he asserts that a little child would never come to the idea ${ }^{24}$ to identify an "object" in its surroundings in order to label it with its first word, "mama." This would be an intellectual operation on a level of abstraction, which obviously is out of reach with the age of one. Instead, what the child experiences, is a situation - the situation of care and love, and this situation is being named by the child: "mama." Therefore, words right from the beginning of our life do not design objects, but express situations. And it is highly questionable, if this would change with the further acquisition of language. Thus, we use the term "semantics" in a specific way. Like phonemes, semantics designate what comes into being only through relationship. We take this "relational" view of cultural phenomena radically seriously.

23 Ludwig Wittgenstein, Tractatus Logico-Philosophicus, trans. Charles K. Ogden (London: Routledge \& Kegan Paul, 1922), 25.

24 Sigmund Freud, Beyond the Pleasure Principle, ed. and trans. James Strachey (New York: W. W. Norton \& Company, 1961), 8-11. 
xxvi $\mid$ Introduction

Meaning is not a "quality" of a word but the full dimension of relationship which underlies it.

Language is, no doubt, a relationship. So far, it is sufficient to mention that Ferdinand de Saussure laid the foundation to modern linguistics with the rejection of Young grammarian theory. The Young grammarians believed in an "objective" linguistics, while de Saussure stated that a sign is the expression of a relationship and therefore neither subjective nor objective. "Parasème" (the mental aspect of the sign) and "aposème" (the phonic aspect of the sign) are not two "entities" (A and B) to be synthesized by speech. These aspects are outcomes of the linguistic activity itself and do not exist without it. This statement began the "semiotic turn," which was, among others, a turn from the futile attempt to designate linguistics as a natural science to assigning it to be a role model within the humanities. In consequence, phonology discovered that even the sound aspect of language is not of a "material" but of purely a relational character. The region of relationships reaches out farther than you might have expected. But this volume has not the task to resume the findings of the "semiotic turn", which are well documented. Instead, it shall, among others, demonstrate that even semiotics - though also claimed to be the universal meta-science of all fields in the humanities-is not in a position to rule over the other sciences of relationships. First, because none of the sciences of relationships is in an absolute meta-position in relation to the others. They are all interrelated with each other, and their relations do not form hierarchies, but analogies or equivalences. The world of different forms of relationships is guided by the principle of resemblance. Unfortunately, this status entraps us to construct virtual hierarchies between them-for example, as we have seen, in psychologism or in the philosophy of language. On the basis of their universal resemblance, any interrelation between different fields of relationship can be reframed as a hierarchy between them, if only you change into the hierarchical (subject-object) mode of argument. This happens quite often and in every case it looks rather convincing, because many people cannot imagine relationships other than hierarchies. Not only psychology, philosophy of language and semiotics claimed to be the "leading" disciplines in the humanities, but also history, sociology, cultural studies, not to mention philosophy (much, much earlier, however).

The second reason why semiotics is not the answer to the question for a general principle of the humanities is, that it hasn't developed neither an understanding of time, and therefore cannot be accepted by the historical disciplines, nor an understanding of the other, which is the reason for their 
rejection by sociology and psychology. ${ }^{25}$ Moreover, semiotics were not able to develop a full understanding of relationships, because usually it is based on a triadic model ("icon, index, symbol" or "term, proposition, argument" or "signifier, signified, denoted"). However, a fully "relational" view of language implies at least two dimensions of relation and therefore at least four statuses. As in Boolean algebra, and as in the example mentioned above, in relationships minimally given are four statuses: the truth of both, the untruth of both, untruth on one side combined with truth on the other side, and vice versa.

A way towards a fully developed four-dimension understanding of the sign was put forth by Roman Jakobson. In order to understand his effort, we should realize more consequently the dimensions of the sign as generators of connections on different levels. Under these auspices, the signifier connects sounds, the signified connects concepts, the denoted connects notions of reality, and the aesthetic dimension of the sign, which Jakobson added without making clear its position with respect to the other three, connects the sign with other signs, producing the semantic field. As we see, semiotics is dealing with relationships, and by this it qualifies for being part of the humanities, but not for being the leading discipline of them all.

Dialogicity, thus, is the one common quality of phenomena expressing relationships. Therefore, a dialogical approach should be the universal tool of understanding them. To examine phenomena of relationship is the long-sought common quality of the various disciplines within humanities. However, this quality, and with it the very nature of such phenomena, dissolves when we, conditioned by natural sciences, redefine relationships as objects. For this reason, all disciplines in the humanities are called to develop dialogical approaches, which are the most adequate to the phenomena they examine-be it psychic, social, cultural, epistemological or historical. With the presented volume, we try to give an impetus to such approaches. Some of the contributors of this volume formed the panel "Dialogical Humanities" at the fifteenth International Bakhtin conference held in Stockholm in July 2014.

25 Cf. Matthias Freise, „Vier Weisen nach dem Text zu fragen“ [Four ways to inquire after the text], in Finis coronat opus, Festschrift für Walter Kroll zum 65. Geburtstag (Göttingen: Universitätsverlag, 2006), 74-75. 


\section{References}

Cassirer, Ernst. Substance and function and Einstein's theory of relativity. London: The Open Court Publishing Company, 1923.

Derrida, Jacques. La voix et la phénoméne. Introduction au problème du signe dans la phénoménologie de Husserl [Speech and Phenomena: And Other Essays on Husserl's Theory of Signs]. Paris: Presses universitaires de France, 1967.

Dilthey, Wilhelm. „Ideen über eine beschreibende und zergliedernde Psychologie“ [Ideas On a Describing and Parsing Psychology]. In: Gesammelte Schriften, vol. 5, 139-240. Berlin: Teubner, 1924.

Freise, Matthias. Michail Bachtins philosophische Ästhetik der Literatur [Mikhail Bakhtin's philosophical aesthetics of literature]. New York: Peter Lang, 1993.

Freise, Matthias. „Vier Weisen nach dem Text zu fragen“ [Four ways to inquire after the text]. In Finis coronat opus, Festschrift für Walter Kroll zum 65. Geburtstag, 71-84. Göttingen: Universitätsverlag, 2006.

Freud, Sigmund. "Advice to Doctors on Psychoanalytic Treatment." In Wild Analysis, translated by Alan Bance, 31-42. London: Penguin, 2002.

Freud, Sigmund. Beyond the Pleasure Principle. Edited and translated by James Strachey. New York: W.W. Norton \& Company, 1961.

Gadamer, Hans Georg. Wahrheit und Methode. Tübingen: Mohr, 1965. Translated by Joel Weinsheimer and Donald G. Marshall as Truth and Method (London: Sheed and Ward, 1989).

Gauthier, Yvon. Internal Logic. Foundations of Mathematics from Kronecker to Hilbert. Dordrecht, Boston, London: Springer, 2002.

Grondin, Jean. Einführung in die philosophische Hermeneutik. Darmstadt: Wissenschaftliche Buchgesellschaft, 1991. Translated by Joel Weinsheimer as Introduction to Philosophical Hermeneutics (New Haven: Yale University Press, 1994).

Habermas, Jürgen. Theorie des kommunikativen Handelns. Frankfurt am Main: Suhrkamp, 1981.

Translated by Thomas McCarthy as Theory of Communicative Action (Boston: Beacon Press, 1984-1987).

Heidegger, Martin. Die Frage nach dem Ding [The question concerning the thing]. Tübingen: Niemeyer, 1962. 
Ivanov, Vjacheslav I. "The Significance of M. M. Bakhtin’s Ideas on Sign, Utterance, and Dialogue for Modern Semiotics." Soviet Studies in Literature 11, issue 2-3 (1975): 186-243.

Kołakowski, Leszek. Husserl and the Search for Certitude. New Haven: Yale University Press, 1975.

Merleau-Ponty, Maurice. Phénoménologie de la perception [Phenomenology of perception]. Paris: Gallimard, 1945.

Mill, John Stuart. Examination of Sir William Hamilton's Philosophy. Vol. 9 of Collected Works. Edited by John M. Robson. Toronto: University of Toronto Press, 1979.

Morson, Gary Saul. “The Heresiarch of META,” PTL III (1978): 379-385.

Rorty, Richard. Philosophy and the Mirror of Nature. Princeton: Princeton University Press, 1979.

Voloshinov, Valentin. Freidizm. New York: Chalidze, 1983.

Windelband, Wilhelm. Geschichte und Naturwissenschaft [History and science]. Straßburg: Heitz, 1894.

Wittgenstein, Ludwig. Tractatus Logico-Philosophicus. Translated by Charles K. Ogden. London: Routledge \& Kegan Paul, 1922. 
